\title{
Best practices in the differential diagnosis and reporting of acute transfusion reactions
}

This article was published in the following Dove Press journal:

International Journal of Clinical Transfusion Medicine

21 January 2016

Number of times this article has been viewed

\author{
Christopher M Hillis ${ }^{1-3, *}$ \\ Andrew W Shih',3,* \\ Nancy M Heddle H,3,4 $^{1,2}$ \\ 'Department of Medicine, \\ ${ }^{2}$ Department of Oncology, ${ }^{3}$ McMaster \\ Transfusion Research Program, \\ McMaster University, Hamilton, \\ ${ }^{4}$ Centre for Innovation, Canadian \\ Blood Services, Ottawa, ON, Canada \\ *These authors contributed equally \\ to this work
}

\begin{abstract}
An acute transfusion reaction (ATR) is any reaction to blood, blood components, or plasma derivatives that occurs within 24 hours of a transfusion. The frequencies of ATRs and the associated symptoms, reported by the sentinel sites of the Ontario Transfusion Transmitted Injuries Surveillance System from 2008 to 2012, illustrate an overlap in presenting symptoms. Despite this complexity, the differential diagnosis of an ATR can be determined by considering predominant signs or symptoms, such as fever, dyspnea, rash, and/or hypotension, as these signs and symptoms guide further investigations and management. Reporting of ATRs locally and to hemovigilance systems enhances the safety of the blood supply. Challenges to the development of an international transfusion reaction reporting system are discussed, including the issue of jurisdiction and issues of standardization for definitions, investigations, and reporting requirements. This review discusses a symptom-guided approach to the differential diagnosis of ATRs, the evolution of hemovigilance systems, an overview of the current Canadian system, and proposes a best practice model for hemovigilance based on a World Health Organization patient safety framework.
\end{abstract}

Keywords: blood transfusion, blood components, hemovigilance

\section{Introduction}

Acute transfusion reactions (ATRs) are adverse events to blood, blood components, or plasma derivatives that occur within 24 hours of administration. Any reaction beyond 24 hours is termed a delayed transfusion reaction. ${ }^{1}$ ATRs occur in $0.5 \%-3 \%$ of transfusions. ${ }^{2}$ While appearing relatively insignificant, one must consider the ubiquitous nature of transfusion therapy, with approximately 1.5 million transfusions per year administered in Canada alone. ${ }^{3}$ Reporting of ATRs is crucial to monitor the safety of one of the most widely used treatments in medicine. ${ }^{4}$

Reporting is performed locally by transfusion medicine services that then report to a regional or national hemovigilance system, if established. A hemovigilance system as defined by the International Hemovigilance Network is "a set of surveillance procedures covering the whole transfusion chain, intended to collect and assess information on unexpected or undesirable effects resulting from the therapeutic use of labile blood products, and to prevent their occurrence or recurrence". ${ }^{5}$ Canada's national voluntary hemovigilance system is the Transfusion Transmitted Injury Surveillance System (TTISS), which was established by the Public Health Agency of Canada (PHAC) in 2001 following recommendations from the Krever report. ${ }^{3}$

Table 1 lists the most common ATRs, their respective frequencies, putative etiologies, clinical presentations, and management. The majority of ATRs reported to submit your manuscript | www.dovepress.com

Dovepress

http://dx.doi.org// 0.2147/IJCTM.S60920
International Journal of Clinical Transfusion Medicine 2016:4 I-I4 (c) (i) (8) 2016 Hillis et al. This work is published by Dove Medical Press Limited, and licensed under Creative Commons Attribution - Non Commercial (unported, v3.0) permission from Dove Medical Press Limited, provided the work is properly attributed. Permissions beyond the scope of the License are administered by Dove Medical Press Limited. Information on how to request permission may be found at: http://www.dovepress.com/permissions.php 


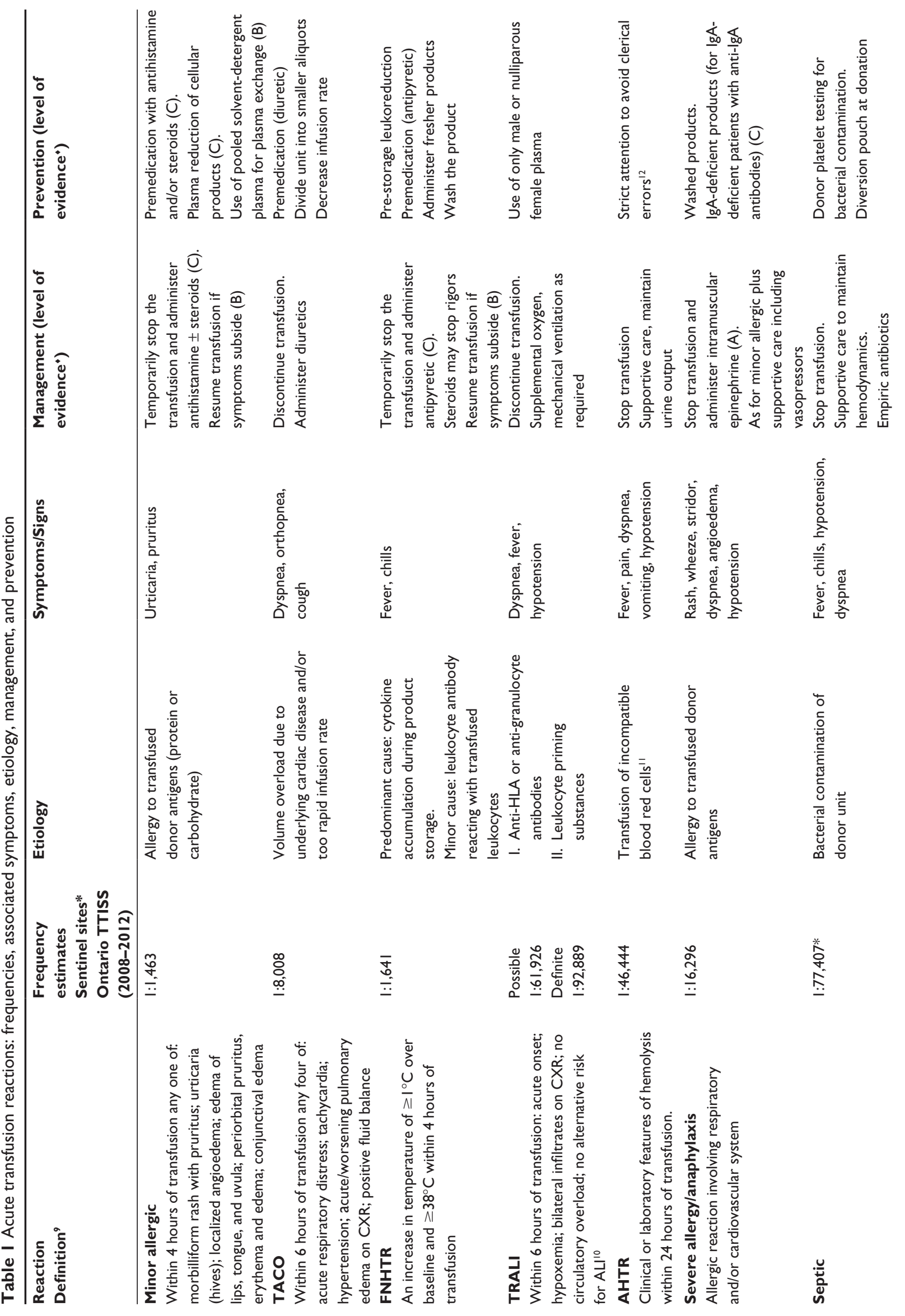




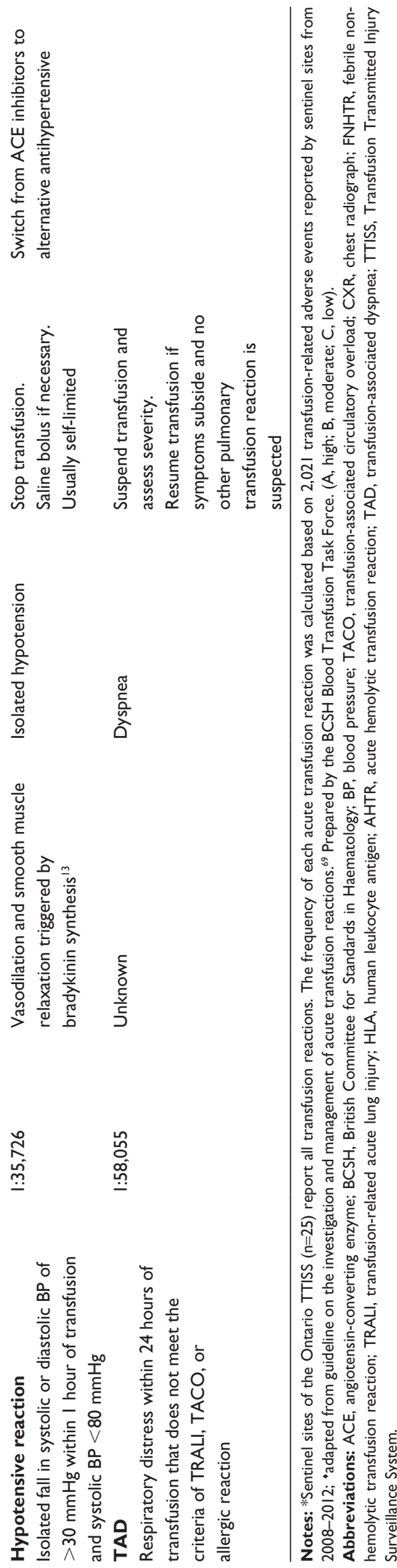

the Canadian TTISS from 2006 to 2012 were non-severe, with $52.1 \%$ of adverse reactions being grade 1 (no medical intervention deemed necessary). ${ }^{6}$ However, ATRs can also be fatal, with a transfusion-related mortality rate of 1 in 322,580 as reported by the UK's Serious Hazards of Transfusion (SHOT) data, and a $0.1 \%$ fatality rate for reported adverse events in the USA from 2010 to 2012.7.8

Standardized definitions of ATRs, investigations, and reporting have varied internationally and over time. This variability makes it difficult to compare data from different hemovigilance systems. Here we discuss current best practices for both identification and reporting of ATRs.

\section{Presentation of ATRs}

ATRs present with a range of overlapping signs and/or symptoms. ${ }^{9}$ For example, a patient who presents with fever during a transfusion may be experiencing a hemolytic transfusion reaction, a febrile non-hemolytic transfusion reaction (FNHTR), a septic transfusion reaction, or transfusion-related acute lung injury (TRALI; Table 1). Upon recognition of any reaction, the default practice should be discontinuation of the transfusion, maintenance of venous access, and rapid clinical assessment. Each ATR must be evaluated in context based on the patient's underlying disease, with strict attention to the clinical status of the patient prior to the transfusion. The blood product should be visually inspected for discoloration or clumping of cells, and a clerical check performed to ensure that the right product is being transfused to the right patient.

Patients should be told to report any reactions they may experience in the 24 hours following a transfusion. Patients unable to report symptoms should be directly monitored. A transfusion may only be resumed with caution if the ATR was felt to be mild, for instance only isolated pruritus or rash. Otherwise, a transfusion reaction investigation should be instituted and the unit not resumed. The British Committee for Standards in Haematology has published guidelines on the investigation and management of ATRs. ${ }^{1}$

\section{Symptom-guided differential diagnosis of ATRs}

A careful review of a patient's history will help to determine if the acute reaction is related to the transfusion or is more likely caused by the patient's underlying condition. Data from Ontario's TTISS illustrates the overlap of presenting symptoms between ATRs. For instance, while fever is often felt to be a sign that differentiates TRALI from transfusionassociated circulatory overload (TACO),${ }^{10}$ it is evident that 
a proportion of patients with TACO will also have fever as a presenting sign (Table 2). These reactions have been characterized previously ${ }^{9,11}$ and are summarized for reference in Table 1.

Despite the complexity, using a symptom-based approach is an effective means to determine the type of ATR. While the range of symptoms and signs in ATRs is broad, the predominant presenting symptom or sign can narrow the differential diagnosis of an ATR. This guides further diagnostic considerations and reporting.

\section{Fever}

Fever associated with an ATR is defined as a rise in temperature $>1^{\circ} \mathrm{C}$ and a temperature $>38^{\circ} \mathrm{C}$ during or up to 4 hours following a transfusion, and has a differential diagnosis of: FNHTRs, acute hemolysis reactions, TRALI, or a bacterial transfusion-transmitted infection (TTI). ${ }^{12}$ The $>1{ }^{\circ} \mathrm{C}$ rise in temperature is not based on evidence, but has been universally accepted as a definition for fever in the context of an ATR. ${ }^{13}$ Fever is usually due to an FNHTR; however, pre-storage leukoreduction has decreased these reactions to less than $2 \%$ of products transfused. ${ }^{14}$ Prior to leukoreduction rates of FNHTRs range from $0.5 \%$ to $38 \%$. $^{15,16}$ Other symptoms of an FNHTR are chills, rigors, and nausea/vomiting, and these may be present in the absence of fever ("atypical" or "afebrile" FNHTR). ${ }^{17}$ If clinical and procedural assessment reveals no concerning features, an antipyretic can be administered and the transfusion resumed with careful observation. ${ }^{1,4}$

Acute intravascular hemolytic transfusion reactions (AHTRs) may also present with fever. AHTRs are a medical emergency because they may progress to disseminated intravascular coagulation, shock, and multi-organ failure. ${ }^{18}$ Patients can present with fever alone or accompanied by chills, dyspnea, back or flank pain, nausea/vomiting, and light-headedness. ${ }^{19}$ Presentation includes hemoglobinuria, hemoglobinemia, absent haptoglobin, increased lactate dehydrogenase, and indirect hyperbilirubinemia. ${ }^{20}$ AHTR caused by antibodies other than $\mathrm{ABO}$ can also present with fever, but signs and symptoms are typically less severe and this reaction is suspected with a lower

Table 2 Ontario's Transfusion Transmitted Injury Surveillance System data on presenting symptoms and associated ATR diagnoses from 2008 to $2012(n=2,834)$

\begin{tabular}{|c|c|c|}
\hline $\begin{array}{l}\text { Primary symptom/sign } \\
\text { (\% of all ATRs) }\end{array}$ & $\begin{array}{l}\text { Five most frequent ATR presenting } \\
\text { with specified symptom }\end{array}$ & $\begin{array}{l}\text { ATR presenting with specified } \\
\text { symptom }\end{array}$ \\
\hline \multirow[t]{5}{*}{ Urticaria (23.3) } & Minor allergic & $87.1 \%$ \\
\hline & Severe allergic & $10.1 \%$ \\
\hline & FNHTR & $0.9 \%$ \\
\hline & Anaphylactic shock & $0.5 \%$ \\
\hline & TACO & $0.3 \%$ \\
\hline \multirow[t]{5}{*}{ Chills/rigors (2I.0) } & FNHTR & $62.4 \%$ \\
\hline & Minor allergic & $7.7 \%$ \\
\hline & TACO & $6.2 \%$ \\
\hline & Severe allergic & $5.5 \%$ \\
\hline & Acute hemolytic transfusion reaction & $3.2 \%$ \\
\hline \multirow[t]{5}{*}{ Dyspnea (13.6) } & TACO & $36.3 \%$ \\
\hline & Severe allergic & $15.5 \%$ \\
\hline & FNHTR & $15.3 \%$ \\
\hline & Minor allergic & $8.0 \%$ \\
\hline & TRALI + possible TRALI & $5.7 \%+4.7 \%$ \\
\hline \multirow[t]{5}{*}{ Fever $(9.1)$} & FNHTR & $83.7 \%$ \\
\hline & Minor allergic & $3.9 \%$ \\
\hline & TACO & $3.9 \%$ \\
\hline & Possible TRALI + TRALI & $1.9 \%+0.8 \%$ \\
\hline & Bacterial infection & $1.9 \%$ \\
\hline \multirow[t]{5}{*}{ Hypoxemia (6.7) } & TACO & $52.1 \%$ \\
\hline & Possible TRALI & $18.9 \%$ \\
\hline & FNHTR & $13.2 \%$ \\
\hline & TRALI & $12.6 \%$ \\
\hline & TAD & $10.0 \%$ \\
\hline
\end{tabular}

Abbreviations: ATR, acute transfusion reaction; FNHTR, febrile non-hemolytic transfusion reaction; TACO, transfusion-associated circulatory overload; TRALI, transfusionrelated acute lung injury; TAD, transfusion associated dyspnea. 
than expected hemoglobin increment following transfusion. ${ }^{12}$ To confirm or exclude an AHTR, a number of procedures/tests should be performed, including: a clerical check at the bedside to identify human error, such as incorrect labeling, sample collection from the wrong patient, or patient misidentification; a positive direct antiglobulin test; and visual presence of free plasma hemoglobin. Additional serological testing of pre and post transfusion samples may be required.

Bacterial TTIs are caused by bacterial contamination of product resulting in sepsis. Patients demonstrate a systemic inflammatory response, including fevers, chills, flushing, nausea/vomiting, dyspnea, tachycardia, and hypotension. ${ }^{21,22}$ Patients can progress to overt shock, disseminated intravascular coagulation, and multi-organ failure. If the inoculum in the product is small, patients may not have symptoms immediately during the transfusion. ${ }^{23}$ Bacterial contamination from transfused red cells typically presents during or shortly after the transfusion; whereas reactions from bacterially contaminated platelets typically have a longer lag between the transfusion and presentation. ${ }^{24}$ Risk is exponentially greater with platelets given room temperature storage.

An acute bacterial TTI is typically associated with a temperature increment of $\geq 2^{\circ} \mathrm{C}$, which may be a useful distinguishing feature as other reactions presenting with fever tend to have a smaller temperature increment. ${ }^{25}$ Differentiating between AHTR and sepsis can be challenging at the bedside; however, hemolytic reactions will usually be characterized by the presence of hemoglobinemia and hemoglobinuria. Red cell products that are contaminated with bacteria may appear discolored, and a Gram stain of the product may be positive. Interventions for treatment of both reaction types can be instituted while awaiting diagnostics to differentiate between them. When bacterial TTI is suspected, it is important to quarantine co-components from the blood donation until culture results are available. Consideration should also be given to alternative life-threatening diagnoses such as
TRALI or anaphylaxis when the clinical picture includes fever and also predominant respiratory or allergic signs and symptoms, respectively.

\section{Dyspnea}

Similar to fever, dyspnea is associated with many ATRs. The differential diagnosis of dyspnea is broad and often complicated by a patient's underlying medical condition. ATRs with dyspnea as a predominant symptom include: TRALI, TACO, transfusion-associated dyspnea (TAD) and anaphylaxis. Dyspnea also occurs with AHTRs and bacterial TTI reactions. Patients complaining of dyspnea should be promptly assessed because ATRs causing dyspnea range from mild to life-threatening.

The symptoms of TRALI range from mild dyspnea to severe non-cardiogenic pulmonary edema with hypoxia, fever, hypotension, and respiratory collapse. The US Food and Drug Administration reports TRALI as the leading identifiable cause of transfusion-related mortality; ${ }^{26}$ however, the incidence of TRALI has decreased by two thirds with the use of plasma only from male donors, nulliparous female donors, or parous female donors with no evidence of alloimmunization. ${ }^{26,27}$

When assessing a patient with acute dyspnea during or shortly following a transfusion, it is challenging to differentiate between TRALI, TACO, and anaphylaxis, because all may have hypoxia. The key to differentiating TRALI from TACO is physical examination findings of volume overload (Table 3 ). Both anaphylaxis and TACO may present with stridor and wheeze, but are quickly differentiated by the presence of hypotension with anaphylaxis.

TACO accounted for one third of adverse reactions reported to the TTISS from 2006 to $2012,{ }^{6}$ and the real incidence is likely higher as TACO is known to be under-reported. Risk factors for TACO are cardiac disease, renal impairment, advanced age, and myocardial infarction. ${ }^{28}$ Diuretics serve as a diagnostic therapeutic intervention to differentiate TACO

Table 3 Differentiating TRALI from TACO

\begin{tabular}{lll}
\hline & TRALI & TACO \\
\hline Product & Plasma or platelets & All blood products, volume-dependent \\
Fever & Present or absent & Typically absent \\
Blood pressure & Hypotension & Hypertension \\
Onset & During or within 6 hours of transfusion & Within 6 hours of transfusion \\
JVP & Normal & Elevated \\
Volume status & Euvolemic & Hypervolemic \\
BNP & Normal & Elevated \\
CXR & Non-cardiogenic pulmonary edema & Cardiomegaly, pulmonary edema, vascular redistribution \\
Response to diuretic & Nil & Clinical improvement \\
\hline
\end{tabular}

Note: Data from Lieberman et al. ${ }^{28}$

Abbreviations: CXR, chest X-ray; TRALI, transfusion-related acute lung injury; TACO, transfusion-associated circulatory overload; JVP, jugular venous pressure; BNP, brain natriuretic peptide. 
from other causes of dyspnea. ${ }^{29}$ Vigilance for and reporting of TACO is important because a significant proportion of events are due to failure to recognize early warning signs or risk factors for TACO. ${ }^{30}$

TAD emerged as an ATR classification to allow hemovigilance systems to report pulmonary transfusion reactions that present with mild dyspnea and do not fit into another reporting category. ${ }^{31}$ TAD is not a pathophysiologic entity and the diagnosis can only be made when a patient has isolated respiratory symptoms temporally related to a transfusion and does not meet criteria for TRALI, TACO, or other ATRs. ${ }^{32}$ Careful review of potential TAD cases is imperative, as illustrated by the New Zealand Blood Service Haemovigilance group who found that upon further review, over half of reported TAD cases actually met criteria for another pulmonary transfusion reaction. ${ }^{33}$ Clinicians need to be vigilant for non-pulmonary ATRs that present with dyspnea (ie, AHTRs, septic transfusion reactions, and allergy/ anaphylaxis). While the category of TAD may separate into different categories once the pathophysiology of individual events are determined, capturing these events ensures that they are not ignored.

\section{Rash and other cutaneous symptoms}

Cutaneous symptoms most often relate to allergic reactions. ${ }^{34}$ When a patient describes skin changes or skin symptoms, clinicians must first determine that this is not the initial presentation of a more severe reaction. Skin changes may occur with AHTRs, disseminated intravascular coagulation, bacterial sepsis, and anaphylactic reactions. ${ }^{1,23}$

The most frequent rash is urticarial (hives), either localized or widespread, and can be associated with pruritus, erythema, flushing, or mild respiratory symptoms (dry cough, wheeze). ${ }^{17,23}$ Other rashes associated with transfusion are maculopapular, erythema, or flushing. Allergic reactions are caused by passive transfer of allergens, including plasma proteins, carbohydrates, and non-plasma proteins, and are mediated by histamine. ${ }^{35,36}$ The incidence of allergic-type reactions varies by blood product but is higher for plasma and platelets owing to higher concentrations of plasma. ${ }^{37}$ Allergic ATRs may also manifest with gastrointestinal symptoms. ${ }^{23}$ Reducing the plasma volume of platelets reduces the risk of allergic ATRs, but may result in some platelet loss and function caused by centrifugation..$^{35}$ Studies assessing pharmacologic prophylaxis of allergic reactions have had mixed results. ${ }^{38-40}$ Currently, there is no standard of practice to prevent recurrent mild allergic reactions. ${ }^{41}$
Patients may describe untoward sensory reactions limited to the skin. Pruritus is often followed by the development of urticarial lesion, but can be the sole manifestation of an allergic ATR. ${ }^{34}$ Tingling may be a prodrome of angioedema, ${ }^{42}$ a localized non-pitting edema of subcutaneous/submucosal tissue indicating an allergic-type ATR. The eyelids and mouth are the most commonly affected tissues but the airway can become compromised. ${ }^{43}$ Tingling, particularly perioral, alternatively can be due to hyperventilation or hypocalcemia caused by citrate anticoagulation during a plasma or red cell exchange procedure. ${ }^{44}$

\section{Hypotension}

Hypotension is a medical emergency and is associated with life-threatening ATRs, including anaphylaxis, bacterial TTI, TRALI, or AHTRs, and non-life-threatening ATRs, such as severe FNHTRs. Isolated hypotension, a diagnosis of exclusion, occurs most often with platelet transfusions and resolves shortly after the transfusion. ${ }^{45}$ It is thought that these reactions are mediated by bradykinin, ${ }^{46,47}$ and patients on angiotensin-converting enzyme inhibitors are more prone to this adverse event. ${ }^{48}$

Transfused protein and carbohydrate antigens likely mediate allergic ATRs, which in their most severe form present as anaphylaxis. ${ }^{49}$ Immune-mediated anaphylactic reactions may occur in recipients with a specific protein deficiency who have formed antibodies to that protein, for instance, a patient with immunoglobulin (Ig)A deficiency and pre-formed IgG or IgE class anti-IgA antibodies. ${ }^{12,50}$ Unlike sepsis, hemolysis, or TRALI, all of which also manifest with dyspnea, anaphylaxis is associated with wheeze, stridor, urticaria, and/or angioedema. ${ }^{51}$ Patients with an anaphylactic ATR should be assessed by an immunologist and in future receive appropriate pre-treatment and modified blood products, as required (ie, washed, IgA-deficient). ${ }^{1}$

\section{Best practices in ATR reporting}

Intervening to prevent morbidity and mortality is the first priority during an ATR and treatment should be directed toward symptoms and signs rather than classification. ${ }^{1}$ For instance, a hypotensive patient requires acute resuscitation with intravenous fluids while the clinician attempts to classify the ATR for more definitive management. Classifying an ATR is challenging, but using a symptom-guided framework can assist clinicians. Focused reporting and communication allows clinicians, hospitals, and blood transfusion services to assist in appropriate investigations, management of future transfusions, and to identify practice concerns. 
National hemovigilance programs make systems-level contributions to transfusion safety. The British Committee for Standards in Haematology and American Association of Blood Banks (AABB) both strongly recommend reporting to national schemes to analyze transfusion hazards and make recommendations for improved safety. ${ }^{1}$ Hemovigilance systems elucidate transfusion practices, trigger research identifying new hazards, and improve patient outcomes. There are limitations, given that ATRs are typically underreported, ${ }^{52}$ variable definitions of adverse events exist, ${ }^{52,53}$ and a European survey reported that few countries verified their accepted reports and that participation in mandatory reporting is not always documented. ${ }^{54}$ Although improving ATR reporting may improve transfusion safety, ${ }^{55}$ hospitals reporting more reactions have not been found to be necessarily safer. ${ }^{56}$ Best practices allow for complete data collection for root cause analysis, data verification, and independent adjudication.

\section{Hemovigilance internationally}

A variety of models for hemovigilance exists internationally. Hemovigilance programs in Canada, France, Germany, and Switzerland are managed by national regulations and oversight. Other models include management by medical societies (the Netherlands, UK) and blood manufacturers (Japan). Even within countries, there are diverse systems. In the USA, the US Food and Drug Administration mandates reporting for fatalities of both donors and recipients and product deficiencies (such as product contamination). Multiple additional hemovigilance-related elements exist in the USA, including federally sponsored multicenter epidemiological studies, such as the Retrovirus Epidemiology Donor Studies ${ }^{57}$ and the National Blood Collection and Utilization Survey developed by the US Centers for Disease Control. ${ }^{58}$ The AABB established the AABB Biovigilance Network in 2008 to harmonize adverse event reporting systems including hemovigilance. ${ }^{59}$ Systems internationally are at different stages of development, with examples of emerging systems in South Africa, Zimbabwe, and Uganda in Africa; Honduras, Ecuador, and Brazil in Central and South America; and the People's Republic of China, Vietnam, and Thailand in Asia. ${ }^{60}$

Efforts to standardize hemovigilance systems began in Europe. After France mandated the reporting of all adverse events in blood recipients (1994) ${ }^{61}$ and the SHOT scheme was developed (1996), ${ }^{7}$ the European Union (EU) legislated the EU Blood Safety Directives. The latter included the establishment and maintenance of blood quality systems to ensure traceability, and a "set of organized surveillance procedures to collect and evaluate information on the adverse or unexpected events or reactions resulting from the collection of blood or blood components". ${ }^{62}$

The Directives led to the development of hemovigilance systems in many European countries, often based on SHOT. All member countries are legislated to report to their competent authority annually all serious adverse reactions and events caused by a process failure (even if the blood product is not transfused). For example, SHOT reports to the Medicines and Healthcare Products regulatory authority. Adverse events occurring in clinical areas not involving laboratory quality issues are not mandatory to report by EU legislation but are reported in $\mathrm{SHOT}^{7}$

\section{Development of international collaborations in hemovigilance}

Even with the advancement of hemovigilance through the Directives, the need for a common structure for blood product safety was identified, which led to the development of the European Haemovigilance Network. Its objectives included information exchange, implementing rapid alerts for compromised blood products, an early warning system, education, process standardization and reporting, data compilation, and further implementation of the European Blood Directive. Its activities also include the harmonization of information and definitions to evaluate differences between countries. ${ }^{63}$ The European Haemovigilance Network has become the International Hemovigilance Network and accepts non-EU associate members. As of 2013, there are 32 member states. ${ }^{5}$

\section{Hemovigilance in Canada: Ontario's system}

Canada was one of the first associate members of the International Hemovigilance Network. ${ }^{63}$ Despite a desire to harmonize systems, each province and territory still has its own protocols for collecting and reporting ATRs to the PHAC reflecting the provincial-based funding model for blood. Standardized definitions and reporting forms are used.

In general, when an ATR is identified at the bedside, the laboratory is contacted to initiate an investigation. The transfusion medicine laboratory director is responsible for overseeing this investigation, which may also involve medical trainees, a transfusion safety officer, or a designee from the transfusion medicine laboratory. Details of the adverse reaction are recorded on the Canadian Adverse Events Transfusion Reporting Form 
developed by PHAC. Information recorded on the PHAC form and definitions for adjudicating the severity of the reaction are summarized in Table 4. Reaction definitions and reporting forms are standardized across Canada. The local transfusion medicine physician is responsible for categorizing the event.

The cause-effect relationship between the transfusion and the ATR is also classified as definite, probable, possible, doubtful, ruled out, or not determined. The Transfusion Medicine Service must immediately report a potential reaction related to blood product quality to the blood supplier (Canadian Blood Services, Héma-Québec). Suspected bacterial contamination must be reported within 24 hours to the supplier, who then reports to Health Canada (the regulator of the blood system). An overview of the guidelines for hospitals to report adverse transfusion events is outlined in Figure 1. Serious adverse events related to purified plasma products are reported directly to the manufacturer, who then reports it to Health Canada. Clinicians, laboratory personnel, blood bank directors, and blood suppliers must all be actively involved in the process of ATR reporting.

The hospital transfusion medicine service submits a complete PHAC form to the Provincial TTISS Office. In Ontario, the provincial TTISS office is located at McMaster University, Hamilton, ON, Canada. The transfer of information can occur either by fax or through a web-based form. At the provincial office, each case is reviewed and if relevant data are missing or the reaction is classified as "not determined", attempts are made to collect missing data and classify the reaction. All cases of suspected TRALI are sent to the blood supplier and an adjudication committee makes a final classification decision. Events classified as "not determined" also undergo adjudication for reclassification purposes. In all other cases,

Table 4 Data collected for adverse transfusion reactions recorded for the Public Health Agency of Canada (PHAC)

\begin{tabular}{|c|c|}
\hline Patient characteristics & Transfusion characteristics \\
\hline Patient demographics & Date and time of occurrence and reporting \\
\hline ABO blood group & Place of transfusion \\
\hline Pregnancy history & Premedication and anesthesia used \\
\hline Transfusion history & Suspected blood/blood components \\
\hline Immunocompromised state & Measures taken (treatments) \\
\hline Patient diagnosis & Hospital procedures involved \\
\hline Other clinical history & Report of possible transfusion related blood-borne infection \\
\hline Signs/Symptoms and lab results & Adjudication of ATR \\
\hline Vitals & ATR diagnostic category \\
\hline \multicolumn{2}{|l|}{ - Temperature, Pulse, Respiration rate, Blood pressure } \\
\hline \multirow[t]{2}{*}{ Chills/rigors } & Severity of adverse event in accordance to proposed ISBT/IHN definitions ${ }^{62}$ \\
\hline & Severity of adverse event in accordance to proposed ISBT/IHN definitions ${ }^{62}$ \\
\hline Urticaria & - Grade I (Non-severe) \\
\hline Other skin rash & - Grade 2 (Severe) \\
\hline Shortness of breath & - Grade 3 (Life-threatening) \\
\hline Hypoxemia (with oxygen saturation) & - Grade 4 (Death) \\
\hline Nausea/vomiting & Outcome of Adverse Event \\
\hline Pain (to be specified by form user) & - Death \\
\hline Jaundice & - Major or long-term sequelae \\
\hline Hemoglobinuria & - Minor or no sequelae \\
\hline Oliguria & - Not determined \\
\hline Diffuse hemorrhage & Relationship of transfusion to recipient's death \\
\hline Shock & Subsequent investigations/actions \\
\hline Other symptoms (to be specified by form user) & Action and description if hospital, equipment/supplies, procedure involved \\
\hline Clinical information for TRALI & Medical follow-up, treatment, or preventative \\
\hline - Chest $\mathrm{X}$-ray results & Measures \\
\hline \multicolumn{2}{|l|}{ - Evidence of circulatory overload } \\
\hline Abnormal laboratory tests & Supplier/manufacturer notified \\
\hline $\begin{array}{l}\text { As determined by the user of the PHAC adverse events reporting } \\
\text { form blood culture results on product and recipient }\end{array}$ & Status of investigation \\
\hline
\end{tabular}

Note: Listed in order of appearance on the PHAC Adverse Events Reporting Form. @ All Rights Reserved. Transfusion Transmitted Injuries Surveillance System User's Manual Version 3.0. Public Health Agency of Canada, 2007. Reproduced with permission from the Minister of Health, 2015.66

Abbreviations: ATR: acute transfusion reaction; TRALI: transfusion-related acute lung injury; PHAC: Public Health Agency of Canada. 


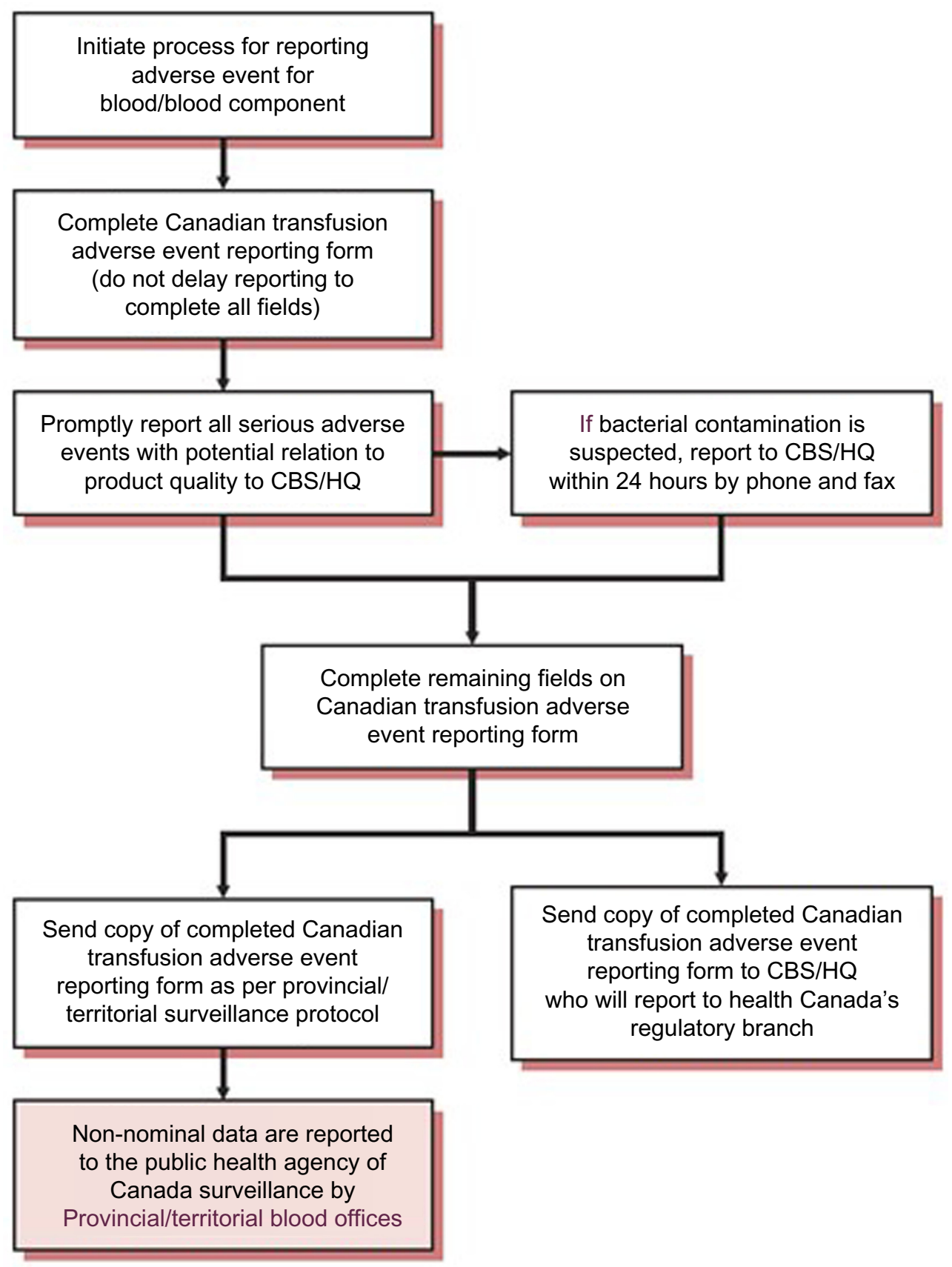

Figure I Flow diagram for hospitals to report adverse events for blood and blood components to provincial/territorial blood offices and Canadian Blood Services/ Hema-Quebec.

Notes: ( All Rights Reserved. Transfusion Transmitted Injuries Surveillance System User’s Manual Version 3.0. Public Health Agency of Canada, 2007. Reproduced with permission from the Minister of Health, 20I5. ${ }^{66}$

Abbreviations: CBS, Canadian Blood Services; HQ, Hema-Quebec.

the hospital's designation as to the type of reaction is the final classification.

Best practice in hemovigilance should include reporting from as many institutions as possible and reporting of all adverse transfusion events. Ontario hospitals participating in TTISS account for $66.2 \%$ of the blood components transfused in the province (49/159 hospitals reporting as of December 2014). Ontario sites not participating in the sentinel site model are only required to report transfusion reactions, which are reportable to PHAC (primary reactions graded as severe). Hence, information is not typically provided on the less severe "non-reportable" ATRs such as delayed serological transfusion reactions, FNHTRs, and minor allergic reactions.

The sentinel site model was introduced in 2009 and includes 25 hospitals in four major health care regions in 


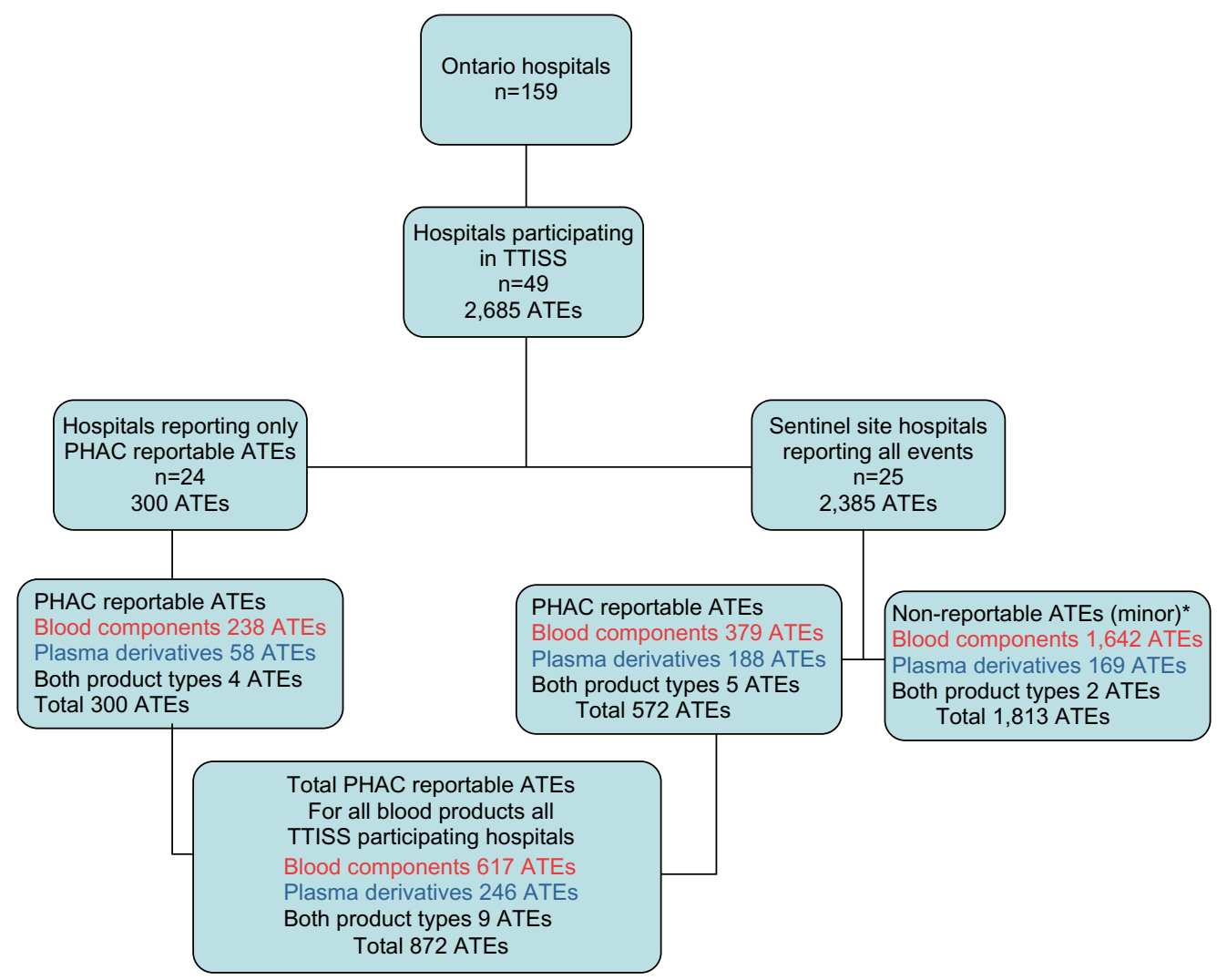

Figure 2 Summary of Ontario hospitals participating in TTISS and ATEs reported.

Notes: Reproduced from Ontario Transfusion Transmitted Injuries Surveillance System (TTISS) Program Report: 2008-2012. McMaster Transfusion Research Program, McMaster University, December 2014. ${ }^{70}$ *includes FNHTR, minor allergic and delayed serologic.

Abbreviations: TTISS, Transfusion Transmitted Injury Surveillance System; ATE, adverse transfusion events; PHAC, Public Health Agency of Canada.

Ontario. These sites are financially compensated to report all ATRs, including these "non-reportable" events, to the Ontario TTISS Office. A summary of the Ontario hospitals participating in TTISS and their contributions are shown in Figure 2.

Ontario's TTISS is a passive hemovigilance system, with hospitals only forwarding cases quarterly when data are requested by PHAC, and there is a 6-month delay in submitting data as cases are still being finalized at the hospital level. Future goals of TTISS in Ontario are to decrease the lag time between collection and reporting, increase participation, and transition into an active reporting system where cases are continually gathered from hospitals and monitored for trends.

\section{Framework for an international standard}

There is a need for standardized reporting of ATRs because currently there is variability in data collection systems, the type of data collected, and definitions, which limit the utility of hemovigilance data. While hemovigilance has been developing internationally, recognition for the need to reduce medical errors has been developing in parallel. The World Health Organization developed the World Alliance for Patient Safety to introduce draft guidelines for adverse event reporting to improve patient safety. These guidelines could serve as a framework for hemovigilance systems. The components and characteristics of a successful reporting system according to the World Health Organization are outlined in Table $5 .^{.64}$

The guidelines state that the design of any reporting system depends on its goals. If the system is built for education, a voluntary system may be better compared with a mandatory system, which is more appropriate for accountability. Hemovigilance programs differ in whether reporting is voluntary or mandatory. Modern hemovigilance systems often will be established for both education and accountability and have a combination of both voluntary and mandatory reporting. In Ontario's TTISS, while learning remains a core focus of the system, incorporating accountability to improve the process of transfusion is necessary. Currently, most non-hemovigilance adverse event reporting systems worldwide are voluntary. 
Table 5 Components and characteristics of successful reporting system as outlined by the WHO World Alliance for Patient Safety draft guidelines for adverse event reporting

\begin{tabular}{|c|c|}
\hline \multicolumn{2}{|c|}{ WHO World Alliance for Patient Safety } \\
\hline \multicolumn{2}{|c|}{ Components of a reporting system } \\
\hline \multicolumn{2}{|c|}{ - Established aim of system } \\
\hline \multicolumn{2}{|c|}{$\begin{array}{l}\text { - Established process of system including types of reports/events } \\
\text { generated }\end{array}$} \\
\hline \multicolumn{2}{|c|}{ - Specification of reporting process } \\
\hline \multicolumn{2}{|c|}{ - Design of a classification system } \\
\hline \multicolumn{2}{|c|}{ - Hazard and systems analysis } \\
\hline \multicolumn{2}{|c|}{ Characteristics of successful reporting systems } \\
\hline Non-punitive & $\begin{array}{l}\text { Reporters are free from fear of } \\
\text { retaliation against themselves or } \\
\text { punishment of others as a result of } \\
\text { reporting. }\end{array}$ \\
\hline Confidential & $\begin{array}{l}\text { The identities of the patient, reporter, } \\
\text { and institution are never revealed. }\end{array}$ \\
\hline Independent & $\begin{array}{l}\text { The reporting system is independent of } \\
\text { any authority with power to punish the } \\
\text { reporter or the organization. }\end{array}$ \\
\hline Expert analysis & $\begin{array}{l}\text { Reports are evaluated by experts who } \\
\text { understand the clinical circumstances } \\
\text { and are trained to recognize underlying } \\
\text { systems causes. }\end{array}$ \\
\hline Timely & $\begin{array}{l}\text { Reports are analyzed promptly } \\
\text { and recommendations are rapidly } \\
\text { disseminated to those who need to } \\
\text { know, especially when serious hazards } \\
\text { are identified. }\end{array}$ \\
\hline Systems-oriented & $\begin{array}{l}\text { Recommendations focus on changes } \\
\text { in systems, processes, or products, } \\
\text { rather than being targeted at individual } \\
\text { performance. }\end{array}$ \\
\hline Responsive & $\begin{array}{l}\text { The agency that receives reports } \\
\text { is capable of disseminating } \\
\text { recommendations. Participating } \\
\text { organizations commit to implementing } \\
\text { recommendations whenever possible. }\end{array}$ \\
\hline
\end{tabular}

Notes: Copyright $\odot$ 2005. Reproduced with permission WHO. World Alliance For Patient Safety WHO Draft Guidelines For Adverse Event Reporting And Learning Systems: From Information To Action. 2005.67

Reporting systems may either attempt to capture adverse events along the entire course of care delivery or may focus on particular types of events. While many hemovigilance systems focus particularly on ATRs only, other systems such as SHOT have included "near misses". SHOT demonstrated that human error accounts for the majority of non-FNHTR adverse transfusion events. ${ }^{7}$ A future goal of the Ontario TTISS will be to include error-related and "near-miss" events in reporting and to perform root causes analyses of events in a local setting.

Given the collaborative nature of hemovigilance and the complex data transmitted, use of an Internet-based system is necessary going forward. Yet financial barriers exist that impair the widespread adoption of Internet reporting schemes. Multiple infrastructure-related barriers including the lack of an electronic system have been reported in areas such as sub-Saharan Africa. ${ }^{65}$ Ontario has adapted the REDCap (Research Electronic Data Capture; a secure web-based application designed to support data capture for research studies) ${ }^{66}$ for adverse event reporting and exploratory analyses.

A recent $\mathrm{AABB}$ validation study highlights the difficulty in reporting systems' abilities to balance the ease of classification and recognition that what promotes learning in patient safety cannot be defined in discrete data elements. Even with definitions, staff responsible for reporting ATRs classified cases differently from an expert panel..$^{53}$ The utility of hemovigilance systems is dependent on appropriate definitions and reproducible classifications. As international collaboration matures, this will need to be an area of study as discrepancies will hinder comparative reports.

Finally, the World Health Organization guidelines describe methods of learning from reporting, including alerting to significant new hazards, systematically investigating a serious event, collecting large datasets, and performing risk and systems analyses. In Ontario, we are expanding data collection and hope to leverage this to improve underreporting of ATRs, to establish better estimates of risk, and to develop bedside management algorithms.

According to the guidelines, the two largest impediments to the development of a successful process are resourcerelated issues and maintaining confidentiality. ${ }^{64}$ In existing national reporting systems, there is variation in sponsorship, participation, and function. ${ }^{64}$ Systems outside of health care demonstrate that success is more likely when those reporting are not concerned about adverse consequences to themselves or others. This requires a balance between a system that protects the safety of those potentially reporting incidents with the accountability and transparency demanded by the health care system and public.

\section{Summary}

ATRs present in complex clinical scenarios and systems and cases should be managed completely from bedside clinical care to international reporting. We propose a framework such as that outlined in Figure 3.

The first priority is management of the patient. A symptom-based approach to guide treatment and to assist in diagnosis of the patient is recommended. A multidisciplinary team should be involved in collecting characteristics 
Identification of transfusion reaction and management using a symptom-guided

framework

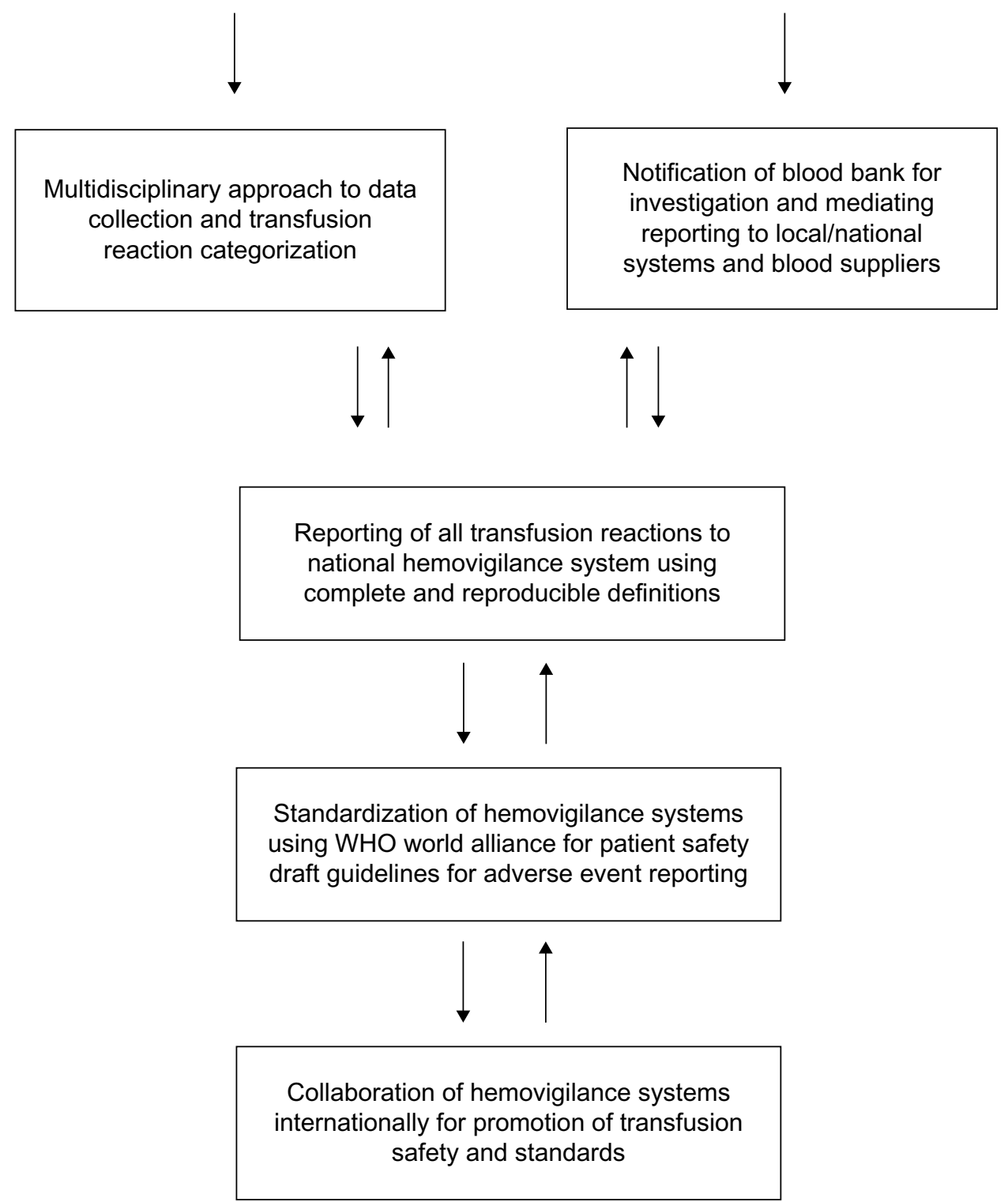

Figure $3 \mathrm{~A}$ framework for the continuous management of adverse transfusion events. Abbreviation: WHO, World Health Organization.

of the case and collaborating to adjudicate the accurate classification of the ATR. We recommend that all ATR cases be collected in a mandatory national hemovigilance system, preferably an active surveillance system.

The WHO World Alliance for Patient Safety draft guidelines for adverse event reporting is a framework that could be used with successful aspects of other hemovigilance systems to standardize practice. Definitions of ATRs must be standardized internationally to make comparisons between jurisdictions meaningful. In addition, countries with mature hemovigilance systems must provide support to countries seeking to develop hemovigilance systems. Successful individual hemovigilance systems have been established, but to advance transfusion safety, international collaborations are needed to establish optimal transfusion practices and reporting worldwide.

\section{Acknowledgments}

CMH is supported by a fellowship provided by the Department of Oncology, McMaster University. AWS is supported by a fellowship provided by Canadian Blood Services. The McMaster Transfusion Research Program receives partial infrastructure funding from Canadian Blood Services and 
Health Canada, and funding from the PHAC and the Ministry of Health and Long Term Care in the province of Ontario to coordinate TTISS activities in the province. We would like to acknowledge Joanne Duncan at the McMaster Transfusion Research Program for providing the data from the Ontario TTISS database and Laura Wong for her administrative support.

\section{Disclosure}

The authors report no competing financial interests in this work.

\section{References}

1. Tinegate H, Birchall J, Gray A, et al. Guideline on the investigation and management of acute transfusion reactions. Prepared by the BCSH Blood Transfusion Task Force. Br J Haematol. 2012;159(2): 143-153.

2. Kato H, Uruma M, Okuyama Y, et al. Incidence of transfusion-related adverse reactions per patient reflects the potential risk of transfusion therapy in Japan. Am J Clin Pathol. 2013;140(2):219-224.

3. Ditomasso J, Liu Y, Heddle NM. The Canadian Transfusion Surveillance System: what is it and how can the data be used? Transfus Apher Sci. 2012;46(3):329-335.

4. World Health Organization. Global blood safety and availability fact sheet no 279. 2009. Available from: http://www.who.int/mediacentre/ factsheets/fs279/en/. Accessed July 10, 2015.

5. International Haemovigilance Network. Definition of Haemovigilance. 2010. Available from: http://www.ihn-org.com/about/definition-ofhaemovigilance/. Accessed January 13, 2015.

6. Mounchili A, Leduc S, Archibald C, Miller J, Hyson C. A summary of the Transfusion Transmitted Injuries Surveillance System: 2006-2012. Can Commun Dis Rep. 2014;40(18).

7. Bolton-Maggs PH, Cohen H. Serious Hazards of Transfusion (SHOT) haemovigilance and progress is improving transfusion safety. $\mathrm{Br} J$ Haematol. 2013;163(3):303-314.

8. Harvey AR, Basavaraju SV, Chung KW, Kuehnert MJ. Transfusionrelated adverse reactions reported to the National Healthcare Safety Network Hemovigilance Module, United States, 2010 to 2012. Transfusion. November 5, 2014. [Epub ahead of print.]

9. Al-Riyami AZ, Al-Hashmi S, Al-Arimi Z, et al. Recognition, investigation and management of acute transfusion reactions: consensus guidelines for Oman. Sultan Qaboos Univ Med J. 2014;14(3):e306.

10. Skeate RC, Eastlund T. Distinguishing between transfusion related acute lung injury and transfusion associated circulatory overload. Curr Opin Hematol. 2007;14(6):682-687.

11. Torres R, Kenney B, Tormey CA. Diagnosis, treatment, and reporting of adverse effects of transfusion. Lab Med. 2012;43(5): 217-231.

12. Choate J. Transfusion reactions to blood and cell therapy products. In: Hoffman R, Benz EJ Jr, Silberstein LE, Heslop H, Weitz J, Anastasi J, editors. Hematology: Basic Principles and Practice. Philadelphia, PA, USA: Elsevier Health Sciences; 2012.

13. Mackowiak PA, Wasserman SS, Levine MM. A critical appraisal of 98.6F, the upper limit of the normal body temperature, and other legacies of Carl Reinhold August Wunderlich. JAMA. 1992;268(12): $1578-1580$.

14. Heddle N, Blajchman M, Meyer R, et al. A randomized controlled trial comparing the frequency of acute reactions and post transfusion platelet recovery of plasma removed and pre-storage leukoreduced platelets. Transfusion. 2002;42(5):556-566.

15. Heddle NM. Universal leukoreduction and acute transfusion reactions: putting the puzzle together. Transfusion. 2004;44(1):1-4.
16. Paglino JC, Pomper GJ, Fisch GS, Champion MH, Snyder EL. Reduction of febrile but not allergic reactions to RBCs and platelets after conversion to universal prestorage leukoreduction. Transfusion. 2004;44(1):16-24.

17. Popovsky MA. Transfusion Reactions. Bethesda, MD, USA: American Association of Blood Banks Press; 2012.

18. Mazzei CA, Popovsky MA, Kopko PM. Noninfectious complications of blood transfusion. Technical Manual. 16th ed. Bethesda, MD, USA: American Association of Blood Banks; 2008.

19. Davenport RD. Hemolytic transfusion reactions. Rossi's Principles of Transfusion Medicine. 4th ed. Oxford, UK: American Association of Blood Banks Press, Wiley-Blackwell; 2009.

20. Popovsky MA, Robillard P, Schipperusm M, Tissot J-D, WiersumOseelton J. Proposed standard definitions for surveillance of noninfectious transfusion reactions. Available from: http://www.ihn-org. com/wp-content/uploads/2011/06/ISBT-definitions-for-non-infectioustransfusion-reactions.pdf. Accessed March 12, 2015.

21. Ramirez-Arcos S, Goldman M, Blajchman M. Bacterial contamination. In: Popovsky MA, editor. Transfusion Reactions. Bethesda, MD, USA: American Association of Blood Banks Press, Wiley-Blackwell; 2007.

22. Matot I, Sprung CL. Definition of sepsis. Intensive Care Med. 2001; 27(14):S3-S9.

23. Callum J, Lin Y, Pinkerton P, et al. Bloody Easy 3: Blood Transfusions, Blood Alternatives and Transfusion Reactions, A Guide To Transfusion Medicine. 3rd ed. Toronto, ON, Canada: Sunnybrook and Women's College Health Sciences Centre; 2011.

24. Mintz PD. Transfusion Therapy: Clinical Principles and Practice. Oxford, UK: American Association of Blood Banks Press, WileyBlackwell; 2005.

25. Hewitt PE. Bacterial contamination. In: Popovsky MA, editor. Practical Transfusion Medicine. Bethesda, MD, USA: American Association of Blood Banks Press, Wiley-Blackwell; 2009.

26. Vlaar AP, Juffermans NP. Transfusion-related acute lung injury: a clinical review. Lancet. 2013;382(9896):984-994.

27. Vlaar AP. Transfusion-related acute lung injury: current understanding and preventive strategies. Transfus Clin Biol. 2012;19(3):117-124.

28. Lieberman L, Maskens C, Cserti-Gazdewich C, et al. A retrospective review of patient factors, transfusion practices, and outcomes in patients with transfusion-associated circulatory overload. Transfus Med Rev. 2013;27(4):206-212.

29. Alam A, Lin Y, Lima A, Hansen M, Callum JL. The prevention of transfusion-associated circulatory overload. Transfus Med Rev. 2013; 27(2):105-112.

30. Piccin A, Cronin M, Brady R, Sweeney J, Marcheselli L, Lawlor E. Transfusion-associated circulatory overload in Ireland: a review of cases reported to the National Haemovigilance Office 2000 to 2010. Transfusion. 2015;55(6):1223-1230.

31. Buxa J, Sachsb U. Pulmonary transfusion reactions. Transfus Med Hemother. 2008;35:337-345.

32. Kleinman SH, Kakaiya R. Acute lung injury after transfusion. Practical Transfusion Medicine. Oxford, UK: John Wiley \& Sons Ltd; 2013.

33. Badami KG, Joliffe E, Stephens M. Transfusion-associated dyspnoeashadow or substance? Vox Sang. April 8, 2015. [Epub ahead of print.]

34. Domen RE, Hoeltge GA. Allergic transfusion reactions: an evaluation of 273 consecutive reactions. Arch Pathol Lab Med. 2003;127(3):316-320.

35. Hirayama F. Current understanding of allergic transfusion reactions: incidence, pathogenesis, laboratory tests, prevention and treatment. Br J Haematol. 2013;160(4):434-444.

36. Matsuyama N, Yasui K, Amakishi E, et al. The IgE-dependent pathway in allergic transfusion reactions: involvement of donor blood allergens other than plasma proteins. Int J Hematol. April 4, 2015. [Epub ahead of print.]

37. Dasararaju R, Marques MB. Adverse effects of transfusion. Cancer Control. 2015;22(1):16-25.

38. Kennedy LD, Case LD, Hurd DD, Cruz JM, Pomper GJ. A prospective, randomized, double-blind controlled trial of acetaminophen and diphenhydramine pretransfusion medication versus placebo for the prevention of transfusion reactions. Transfusion. 2008;48(11):2285-2291. 
39. Sanders RP, Maddirala SD, Geiger TL, et al. Premedication with acetaminophen or diphenhydramine for transfusion with leucoreduced blood products in children. Br J Haematol. 2005;130(5):781-787.

40. Wang SE, Lara PN Jr, Lee-Ow A, et al. Acetaminophen and diphenhydramine as premedication for platelet transfusions: a prospective randomized double-blind placebo-controlled trial. Am J Hematol. 2002; 70(3):191-194.

41. Geiger TL, Howard SC. Acetaminophen and diphenhydramine premedication for allergic and febrile nonhemolytic transfusion reactions: good prophylaxis or bad practice? Transfus Med Rev. 2007;21(1):1-12.

42. Zuraw BL. Clinical practice. Hereditary angioedema. $N$ Engl J Med. 2008;359(10):1027-1036.

43. Kaplan AP, Greaves MW. Angioedema. J Am Acad Dermatol. 2005; 53(3):373-388.

44. Stegmayr B, Ptak J, Wikstrom B. World apheresis registry report. Transfus Apher Sci. 2007;36(1):13-16.

45. Bruno DS, Herman JH. Acute hypotensive transfusion reactions. Lab Med. 2006;37(9):542-545.

46. Hendrickson JE, Hillyer CD. Noninfectious serious hazards of transfusion. Anesth Analg. 2009;108(3):759-769.

47. Cyr M, Eastlund T, Blais C, Rouleau JL, Adam A. Bradykinin metabolism and hypotensive transfusion reactions. Transfusion. 2001; 41(1):136-150.

48. Quillen K. Hypotensive transfusion reactions in patients taking angiotensin-converting-enzyme inhibitors. N Engl J Med. 2000;343(19): $1422-1423$

49. Sandler SG, Eder AF, Goldman M, Winters JL. The entity of immunoglobulin A-related anaphylactic transfusion reactions is not evidence based. Transfusion. 2015;55(1):199-204.

50. Feng ML, Zhao YL, Shen T, et al. Prevalence of immunoglobulin A deficiency in Chinese blood donors and evaluation of anaphylactic transfusion reaction risk. Transfus Med. 2011;21(5):338-343.

51. Sandler SG, Zantek ND. Review: IgA anaphylactic transfusion reactions. Part II. Clinical diagnosis and bedside management. Immunohematology. 2004;20(4):234-238.

52. Narvios AB, Lichtiger B, Neumann JL. Underreporting of minor transfusion reactions in cancer patients. Med Gen Med. 2004;6(2):17.

53. AuBuchon JP, Fung M, Whitaker B, Malasky J. AABB validation study of the CDC's National Healthcare Safety Network Hemovigilance Module adverse events definitions protocol. Transfusion. 2014;54(8): 2077-2083.

54. Wiersum-Osselton JC, Faber JC, Politis C, Brand A, van der Bom JG, Schipperus MR. Quality validation of data in national haemovigilance systems in Europe: report of a survey on current state of practice. Vox Sang. 2013;104(3):214-217.

55. Yeh SP, Chang CW, Chen JC, et al. A well-designed online transfusion reaction reporting system improves the estimation of transfusion reaction incidence and quality of care in transfusion practice. Am J Clin Pathol. 2011;136(6):842-847.

56. Wiersum-Osselton JC, van Tilborgh-de Jong AJ, Zijlker-Jansen PY, et al. Variation between hospitals in rates of reported transfusion reactions: is a high reporting rate an indicator of safer transfusion? Vox Sang. 2013;104(2):127-134.
57. Kleinman S, Busch MP, Murphy EL, Shan H, Ness P, Glynn SA. The National Heart, Lung, and Blood Institute Recipient Epidemiology and Donor Evaluation Study (REDS-III): a research program striving to improve blood donor and transfusion recipient outcomes. Transfusion. 2014;54(3 Pt 2):942-955.

58. US Centers for Disease Control and Prevention. The National Healthcare Safety Network (NHSN) Manual: Biovigilance Component v2.1.3. Available from: http://www.cdc.gov/nhsn/PDFs/Biovigilance/BV-HVprotocol-current.pdf. Accessed January 13, 2015.

59. Strong DM, AuBuchon JP, Whitaker B, Kuehnert MJ. Biovigilance initiatives. ISBT Sci Ser. 2008;3:77-84.

60. Faber JC. Worldwide overview of existing haemovigilance systems. Transfus Apher Sci. 2004;31(2):99-110.

61. Andreu G, Morel P, Forestier F, et al. Hemovigilance network in France: organization and analysis of immediate transfusion incident reports from 1994 to 1998. Transfusion. 2002;42(10):1356-1364.

62. Hansen-Magnusson H. Governance in the European Union: the European Blood Directive as an evolving practice. Clin Lab Med. 2010;30(2):489-497.

63. Strengers P. Haemovigilance - Why? 2003. Available from: http://ihn. withtoast.co.uk/wp-content/uploads/2010/10/Haemovigilance-articleStrengers-P.pdf. Accessed January 14, 2015.

64. World Health Organization: World Alliance For Patient Safety: WHO Draft Guidelines For Adverse Event Reporting And Learning Systems. 2005. Available from: http://www.who.int/patientsafety/events/05/ Reporting_Guidelines.pdf. Accessed January 16, 2015.

65. Meza BP, Lohrke B, Wilkinson R, et al. Estimation of the prevalence and rate of acute transfusion reactions occurring in Windhoek, Namibia. Blood Transfus. 2014;12(3):352-361.

66. Harris PA, Taylor R, Thielke R, Payne J, Gonzalez N, Conde JG. Research electronic data capture (REDCap) - a metadata-driven methodology and workflow process for providing translational research informatics support. J Biomed Inform. 2009;42(2):377-381.

67. WHO. World Alliance For Patient Safety WHO Draft Guidelines For Adverse Event Reporting And Learning Systems: From Information To Action. 2005. Available from http://www.who.int/patientsafety/ events/05/Reporting_Guidelines.pdf. Accessed 17 August, 2015.

68. Public Health Agency of Canada. Transfusion Transmitted Injuries Surveillance System User's Manual Version 3.0. 2007. Available from https://www.google.co.nz/url?sa=t\&rct=j\&q=\&esrc=s\&source=web\&c $\mathrm{d}=1 \&$ ved=0CB0QFjAAahUKEwiVoa2Woq_HAhVBGKYKHRdaCPw \&url $=\mathrm{http} \% 3 \mathrm{~A} \% 2 \mathrm{~F} \% 2 \mathrm{Fwww} \cdot$ transfusionmedicine.ca $\% 2 \mathrm{Fsites} \% 2 \mathrm{Ftran}$ sfusionmedicine $\% 2$ Ffiles $\% 2$ FPDF $\% 2$ FTTISS_Users $\% 2520$ Manual $\% 2$ 5203.0.pdf\&ei=SmHRVZXUH8GwmAWXtKHgDw\&usg=AFQjCNG V7_ARbDD-QLA7oFhQdWzBimP5rQ. Accessed 17 August, 2015.

69. Tinegate H, Birchall J, Gray A, et al. Guideline on the investigation and management of acute transfusion reactions. Prepared by the $\mathrm{BCSH}$ Blood Transfusion Task Force. Br J Haematol. 2012;159(2):143-153.

70. Ontario Transfusion Transmitted Injuries Surveillance System (TTISS) Program Report: 2008-2012. McMaster Transfusion Research Program, McMaster University, December 2014.
International Journal of Clinical Transfusion Medicine

\section{Publish your work in this journal}

International Journal of Clinical Transfusion Medicine is an international, peer-reviewed, open access, online journal publishing clinicalexperimental, policy-making and evidence-based practices of all topics pertaining to clinical transfusion medicine. Original research, short reports, reviews, case reports and commentaries are invited.
Dovepress

The manuscript management system is completely online and includes a very quick and fair peer-review system, which is all easy to use. Visit http://www.dovepress.com/testimonials.php to read real quotes from published authors. 